Check for updates

Cite this: RSC Adv., 2017, 7, 35666

\title{
Crystal growth and characterization of a mixed laser crystal: $\mathrm{Nd}$-doped $\mathrm{Gd}_{0.89} \mathrm{La}_{0.1} \mathrm{NbO}_{4}$
}

\author{
Shoujun Ding, ${ }^{\text {ab }}$ Qingli Zhang, (DD *a Wenpeng Liu, ${ }^{a}$ Jianqiao Luo, ${ }^{a}$ Fang Peng, ${ }^{a}$ \\ Xiaofei Wang, ${ }^{a}$ Guihua Sun ${ }^{a}$ and Dunlu Sun ${ }^{a}$
}

Herein, a $\mathrm{Nd}$-doped $\mathrm{GdLaNbO}_{4}$ (Nd:GLNO) single crystal has been grown successfully using the Czochralski method. The segregation coefficient of $\mathrm{Nd}^{3+}$ ions in the $\mathrm{Nd}$ :GLNO crystal is measured to be 0.71. The X-ray power diffraction patterns of the Nd:GLNO crystal confirm that the as-grown crystal has the same crystal structure as pure $\mathrm{GdNbO}_{4}$. The structural parameters of the as-grown crystal are obtained via an X-ray Rietveld refinement method. The absorption spectrum, fluorescence spectrum, and fluorescence decay curve of Nd:GLNO were obtained at room temperature. The small emission cross-section at $1065 \mathrm{~nm}$ and long fluorescence lifetime of $\mathrm{Nd}^{3+}$ ions (176.4 $\left.\mu \mathrm{s}\right)$ indicate that the $\mathrm{Nd}$ :GLNO crystal is suitable for generating an ultrashort pulse laser. A maximum continuous wave (CW) laser output power of $957 \mathrm{~mW}$ is achieved at $1.06 \mu \mathrm{m}$, corresponding to an optical-to-optical conversion efficiency of $30.3 \%$ and slope efficiency of $34.2 \%$. All the obtained results imply that this crystal is a novel mixed niobate-based laser host suitable for laser diode pumps.

Received 12th May 2017

Accepted 3rd July 2017

DOI: 10.1039/c7ra05380k

rsc.li/rsc-advances narrow absorption bandwidths that limit their application in pulse lasers, especially in ultrashort pulse lasers.

Nowadays, ultrashort pulse laser technology is one of the research hotpots in the laser field, which has been broadly applied in laser micromachining, medical science, optical trapping, etc. ${ }^{13-16}$ For laser materials, the most important requirement to generate an ultrashort pulse laser is the presence of a broad fluorescence band. ${ }^{17,18}$ Generally, spectral bandwidth consists of homogeneous broadening and inhomogeneous broadening. ${ }^{19}$ The inhomogeneous broadening is mainly affected by the crystalline field surrounding the active ions. $^{20}$ Therefore, it has been theoretically and experimentally verified that a mixed crystal can effectively broaden the spectra and generate ultrashort pulse lasers. In 1996, the first mixed vanadate crystal $\left(\mathrm{Nd}: \mathrm{Gd}_{0.5} \mathrm{La}_{0.5} \mathrm{VO}_{4}\right)$ with broad fluorescence spectrum was grown and investigated. ${ }^{21}$ Thereafter, many other Nd-doped mixed vanadate crystals, such as $\mathrm{Nd}: \mathrm{Y}_{1-x} \mathrm{La}_{x}{ }^{-}$ $\mathrm{VO}_{4}, \mathrm{Nd}: \mathrm{Gd}_{x} \mathrm{Y}_{1-x} \mathrm{VO}_{4}$, and $\mathrm{Nd}: \mathrm{Lu}_{x} \mathrm{Gd}_{1-x} \mathrm{VO}_{4}$, were also investigated. $^{22-24}$ More recently, Nd-doped niobate (Nd:GdYNbO ${ }_{4}$ ) and tantalate $\left(\mathrm{Nd}: \mathrm{GdYTaO}_{4}\right)$ mixed laser crystals were successfully grown by the $\mathrm{Cz}$ method, with large inhomogeneous broadened spectra and good laser properties. ${ }^{25,26}$ Among these mixed laser crystals, the $\mathrm{La}^{3+}$-doped crystal is most interesting because $\mathrm{La}$ is the first element in the lanthanide series and has the largest diameter. Therefore, Ladoped mixed crystals may have a more disordered structure and broader fluorescence bandwidth. However, it is generally known that La-doped mixed crystals are very difficult to grow, and, to the best of our knowledge, there are no reports on Ladoped niobate laser crystals.
${ }^{a}$ Anhui Institute of Optics and Fine Mechanics, Chinese Academy of Sciences, Hefei 230031,PR China.E-mail: zql@aiofm.ac.cn; 18119616997@163.com

${ }^{b}$ University of Science and Technology of China, Hefei 230026, PR China 
In this study, a $\mathrm{Nd}: \mathrm{GdLaNbO}_{4}$ mixed laser crystal was successfully grown via the $\mathrm{Cz}$ method for the first time. Its structure, crystalline quality, absorption spectrum, and fluorescence spectrum were systematically investigated. An efficient laser diode end-pumped CW laser operation at $1066 \mathrm{~nm}$ was also demonstrated.

\section{Experiment details}

\subsection{Crystal growth}

The compounds $\mathrm{Nd}_{2} \mathrm{O}_{3}$ (99.999\%), $\mathrm{Gd}_{2} \mathrm{O}_{3}$ (99.999\%), $\mathrm{La}_{2} \mathrm{O}_{3}$ (99.99\%), and $\mathrm{Nb}_{2} \mathrm{O}_{5}$ (99.99\%) were used as starting materials to grow the Nd:GdLaNbO 4 laser crystal via the conventional $\mathrm{Cz}$ technique using JGD-60 furnace ( $26^{\text {th }}$ institute of CETC, China). The starting materials were accurately weighed according to the chemical formula $\mathrm{Nd}_{0.01}: \mathrm{Gd}_{0.89} \mathrm{La}_{0.1} \mathrm{NbO}_{4}$ (all components were dried before weighing). After being adequately mixed and pressed into tablets, the raw materials were loaded into an iridium crucible. To prevent iridium from oxidation, the crystal was grown in a sealed chamber under a nitrogen atmosphere. A $a$-orientated $\mathrm{GdNbO}_{4}$ crystal bar was used as the seed crystal. The pulling rate and rotation speed were $0.5-1 \mathrm{~mm} \mathrm{~h}^{-1}$ and 5$10 \mathrm{rpm}$, respectively. After the growth process ended, the crystal was cooled down to room temperature at a rate of $30-40{ }^{\circ} \mathrm{C} \mathrm{h}^{-1}$. Afterwards, a Nd:GLNO crystal boule was obtained, as shown in Fig. 1. As can be seen, the crystal is free from cracks and pink in color. Under a $532 \mathrm{~nm}$ laser, no obvious scattering was found for the as-grown crystal. Before cutting the as-grown crystal for experiments, it was oriented in three crystallographic orientations.

\subsection{Characterization}

The X-ray diffraction (XRD) patterns of the Nd:GLNO crystal powder were obtained via the Philips X'pert PRO X-ray diffractometer using $\mathrm{Cu} \mathrm{K} \alpha$ radiation in the $2 \theta$ range of $10-90^{\circ}$ at a step rate of $0.02^{\circ} \mathrm{min}^{-1}$. The X-ray rocking curves were obtained by a high-resolution X'pert Pro MPD diffractometer with a hybrid $\mathrm{K} \alpha_{1}$ monochromator. X-ray fluorescence analysis (XRF-1800) was conducted to measure the elemental concentrations of $\mathrm{Nd}^{3+}$ in the as-grown crystal. The transmission spectrum of

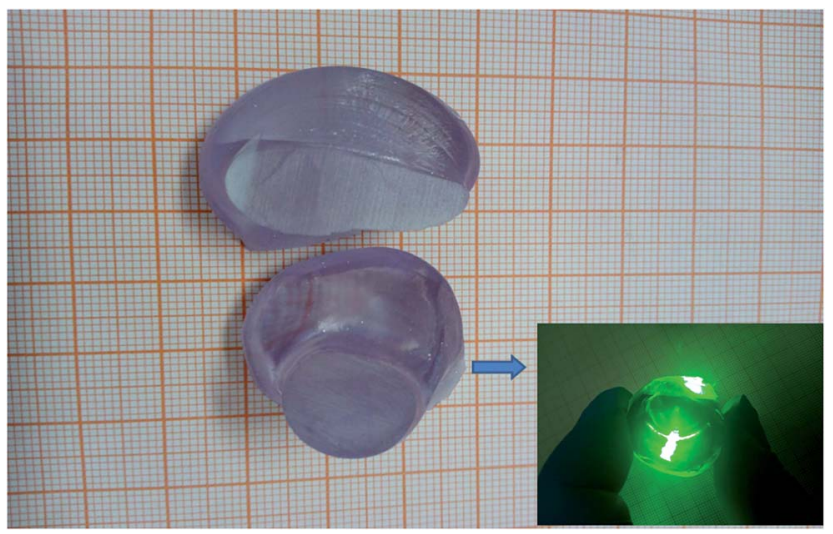

Fig. 1 Image of the as-grown $\mathrm{Nd}: \mathrm{GdLaNbO}_{4}$ laser crystal.
Nd:GLNO in the wavelength range of 320-950 nm was obtained by a Perkin-Elmer lambda-950 spectrophotometer at a spectral interval of $1 \mathrm{~nm}$. The fluorescence spectra with $0.5 \mathrm{~nm}$ spectral interval were obtained from 850 to $1400 \mathrm{~nm}$ by an Edinburgh fluorescence spectrometer (FLSP-920) with a Xe lamp as the excitation source. The fluorescence decay curve of Nd:GLNO was also obtained using an FLSP-920 spectrometer with a microsecond lamp as the excitation source.

\subsection{Laser experiment}

Diode pumped continuous wave laser experiment at $1.06 \mu \mathrm{m}$ was performed using an uncoated $2 \mathrm{~mm} \times 2 \mathrm{~mm} \times 5 \mathrm{~mm}$ $\mathrm{Nd}: \mathrm{GdLaNbO}_{4}$ crystal, in which the $2 \mathrm{~mm} \times 2 \mathrm{~mm}$ faces were cut along the crystallographic $b$-orientation and carefully polished. The configuration for generating $1.06 \mu \mathrm{m}$ laser is shown in Fig. 2. A fiber-coupled $\mathrm{CW}$ laser diode with a maximum output power of $30 \mathrm{~W}$ (central wavelength at around $808 \mathrm{~nm}$ ) was employed as the pumping source. The pump beam was focused on the Nd:GLNO crystal with a spot radius of about 0.22 $\mathrm{mm}$ through the focusing optics. M1 is a plane mirror, with an antireflection (AR) material coated at $808 \mathrm{~nm}$ on the pump side, a high reflection (HR) material coated at $1.06 \mu \mathrm{m}$, and a high transmission (HT) material coated at $808 \mathrm{~nm}$ on the other face. M2 is the output couple, with a transmission of $5.4 \%$ at 1.06 $\mu \mathrm{m}$. During the laser experiment, the crystal was wrapped with an indium foil and mounted on a copper block cooled by deionized water. For cooling, deionized water was maintained at $20{ }^{\circ} \mathrm{C}$. The output laser power was measured using an OPHIR 30A-BB-18 power meter.

\section{Results and discussion}

\subsection{Crystal structure and quality}

The XRD patterns of the as-grown Nd:GLNO crystal are shown in Fig. 3. As can be seen, the diffraction peaks in the XRD patterns of Nd:GLNO can be well indexed with those in ICSD\#20408, suggesting that the as-grown crystal has the same crystal structure as the M-type $\mathrm{GdNbO}_{4}$, with a space group of $I 2 / a$. The structural parameters of the Nd:GLNO crystal were obtained by fitting the XRD data using the Rietveld refinement method via the general structure analysis software (GSAS), ${ }^{27}$ and the structural parameters of ICSD\#20408 were used as the initial values. The Rietveld refinement results of the Nd:GLNO crystal are shown in Fig. 4. The residual $R_{\mathrm{p}}$ and $R_{\mathrm{wp}}$ are $5.86 \%$ and $4.20 \%$, respectively, which indicate that the refined results are reliable. The unit cell parameters of Nd:GLNO are fitted to be $a=5.381$ $\AA, b=11.112 \AA, c=5.112 \AA, \alpha=\gamma=90^{\circ}$, and $\beta=94.551^{\circ}$. Compared with Nd:GNO ( $a=5.372 \AA, b=11.093 \AA$, $c=5.107)$

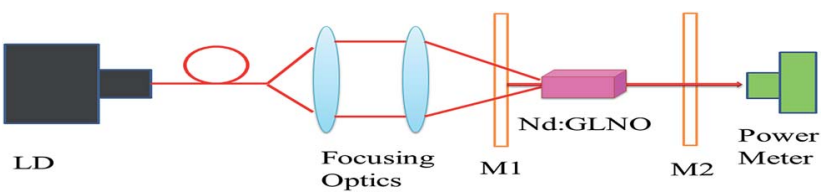

Fig. 2 Schematic of the experimental laser setup. 


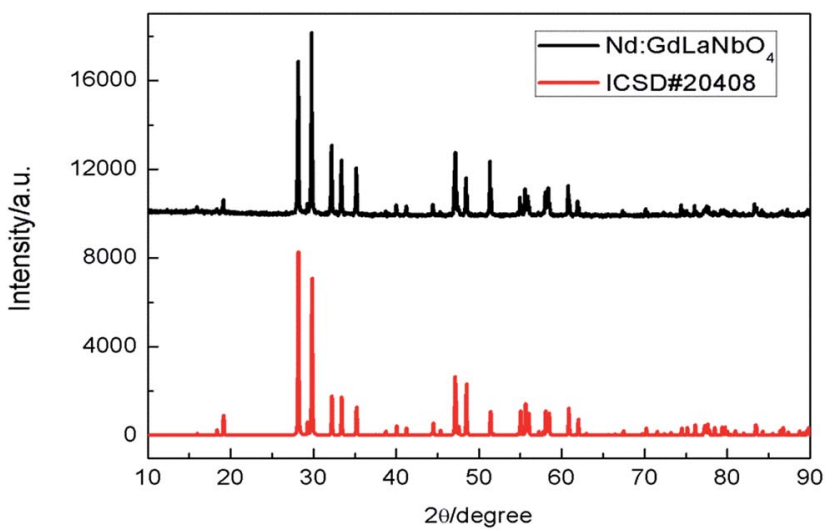

Fig. 3 XRD diffraction patterns of the $\mathrm{Nd}: \mathrm{GdLaNbO}_{4}$ crystal and $\mathrm{GdNbO}_{4}$ obtained from ICSD\#20408.

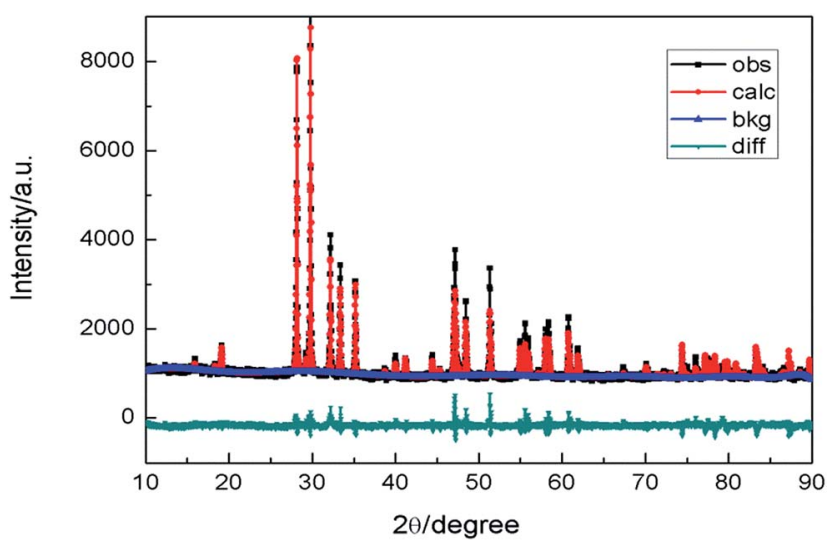

Fig. 4 The Rietveld refinement results of Nd:GLNO crystal (obs: the observed data; calc: calculated data; bkg: the background; diff: the difference between observed and calculated data).

and Nd:GYNO $(a=5.349 \AA, b=11.049 \AA, c=5.097)$ crystals, the unit-cell of Nd:GLNO is largest because the ionic radius of $\mathrm{La}^{3+}$ $(1.15 \AA)$ is larger than those of $\mathrm{Gd}^{3+}(0.94 \AA)$ and $\mathrm{Y}^{3+}(0.9 \AA)$.

The $\mathrm{X}$-ray rocking curves of the as-grown crystal are shown in Fig. 5. The diffraction peak shows a symmetric shape without splitting, suggesting that the as-grown crystal does not have a twin structure. Additionally, the full width at half-maximum (FWHM) values of the diffraction peak are $0.053^{\circ}, 0.101^{\circ}$, and $0.0457^{\circ}$, which indicate high crystalline quality of the as-grown crystal.

\subsection{Effective segregation coefficients}

The concentrations of $\mathrm{Nd}^{3+}$ and $\mathrm{La}^{3+}$ ions in the as-grown Nd:GLNO crystal were measured using the XRF analysis. A slice for the measurement was cut in the shoulder part of the asgrown crystal. The effective segregation coefficients of $\mathrm{Nd}^{3+}$ and $\mathrm{La}^{3+}$ are calculated to be 0.71 and 0.47 , respectively, according to the equation $k_{\text {eff }}=C_{\mathrm{s}} / C_{\mathrm{l}}$, where $C_{\mathrm{s}}$ and $C_{\mathrm{l}}$ are the ion concentration in the crystal and melt, respectively. Generally, the radius difference between the doping and matrix ions have great influence on the effective segregation..$^{28}$ The radii of the

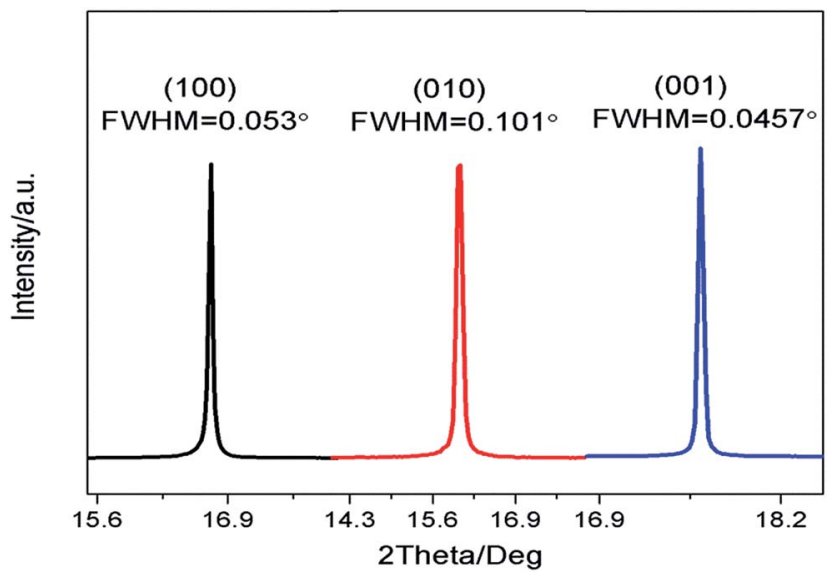

Fig. 5 X-ray rocking curve of the (100), (010), and (001) crystallographic faces.

doping ions are closer or smaller than those of the matrix ions, and the matrix ions are easier to be substituted by the doping ions. In this study, the radius of $\mathrm{Nd}^{3+}(0.98 \AA)$ is closer to that of $\mathrm{Gd}^{3+}(0.94 \AA)$ than that of $\mathrm{La}^{3+}(1.15 \AA)$. Therefore, the effective segregation coefficient of $\mathrm{Nd}^{3+}$ in Nd:GLNO host is quite large and much larger than that of Nd:YAG (0.1-0.2). The large segregation coefficient of $\mathrm{Nd}^{3+}$ in Nd:GLNO host also means that high and uniform $\mathrm{Nd}^{3+}$-doped crystal can be grown via the Cz method. ${ }^{29}$

\subsection{Optical properties}

3.3.1 Absorption spectrum. The samples for the absorption spectrum measurement were cut from the as-grown crystal along the crystallographic axes $a, b$, and $c$. All the samples were polished to a thickness of $2 \mathrm{~mm}$. As can be seen, the room temperature absorption spectrum (Fig. 6) consists of 11 absorption bands in the measured wavelength range, which is associated with the observed transitions from the ${ }^{4} \mathrm{I}_{9 / 2}$ ground state. Via comparing the absorption spectrum of $\mathrm{Nd}^{3+}$ in the

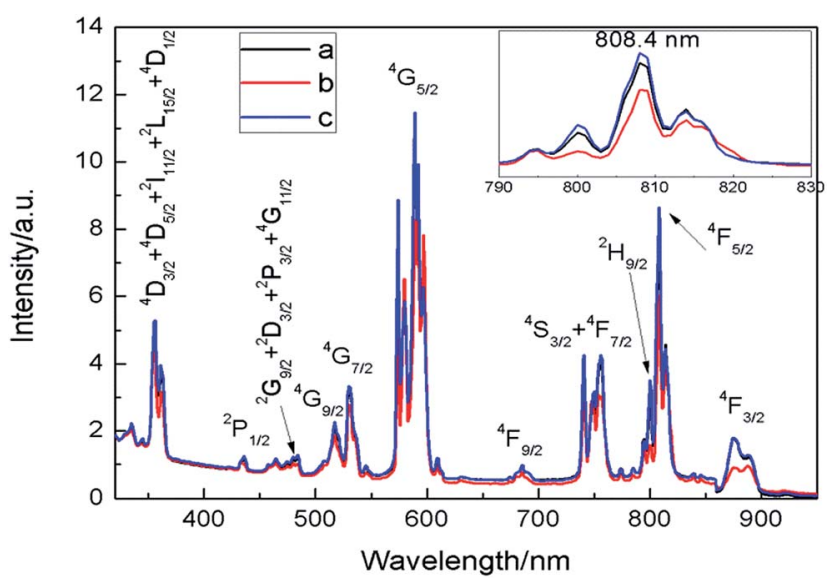

Fig. 6 Room temperature absorption spectra of the Nd:GLNO crystal along three crystallographic orientations. Inset: enlarged absorption spectra at around $808 \mathrm{~nm}$. 
Nd:GLNO crystal with that of $\mathrm{Nd}^{3+}$ in other tantalate and niobate crystals, all the absorption bands are assigned and denoted in Fig. 6. Moreover, the absorption spectra along $a, b$, and $c$ axes show distinct differences, which can be attributed to the anisotropy of monoclinic crystals. The absorption of the Nd:GLNO crystal at $808 \mathrm{~nm}$ with $c$-orientation is strongest among the three orientations with an absorption coefficient of $8.97 \mathrm{~cm}^{-1}$ and an FWHM of about $13 \mathrm{~nm}$. The FWHM of Nd:GLNO is wider than that of Nd:GNO and Nd:YNO (much wider than the $2 \mathrm{~nm}$ of Nd:YAG), indicating that Nd:GLNO crystal can be better matched with commercial AlGaAs laser diode and is advantageous for improving the laser efficiency. Based on the equation $\sigma=\alpha(\lambda) / N_{\mathrm{c}}$, where $\alpha(\lambda)$ is the absorption coefficient and $N_{\mathrm{c}}$ is the concentration of $\mathrm{Nd}^{3+}$ in the Nd:GLNO crystal, the absorption cross section of the Nd:GLNO crystal with $c$-orientation at $808 \mathrm{~nm}$ is estimated to be $10.49 \times 10^{-20}$ $\mathrm{cm}^{2}$. Compared with Nd:GNO and Nd:YNO, Nd:GLNO shows larger absorption cross section at $808 \mathrm{~nm}$ and thus has better absorption of the pumping energy.

3.3.2 Fluorescence spectrum. The room-temperature emission spectrum of the as-grown Nd:GLNO crystal in the wavelength range of $850-1400 \mathrm{~nm}$ is shown in Fig. 7. In the measured wavelength range, three emission bands (central wavelength at $885 \mathrm{~nm}, 1065 \mathrm{~nm}$, and $1330 \mathrm{~nm}$ ) were observed, which corresponded to the ${ }^{4} \mathrm{~F}_{3 / 2} \rightarrow{ }^{4} \mathrm{I}_{J}(J=9 / 2,11 / 2$, and $13 / 2$, respectively) transitions of $\mathrm{Nd}^{3+}$. The comparison between the emission spectra of Nd:GLNO, Nd:GNO, and Nd:YNO crystal at around $1065 \mathrm{~nm}$ is shown in the inset of Fig. 7. Owing to inhomogeneous broadening in the Nd:GLNO crystal, the FWHM of Nd:GLNO ( $5 \mathrm{~nm})$ is widest among these crystals. In addition, stimulated emission cross-section $\left(\sigma_{\text {em }}\right)$ can be estimated from the fluorescence spectra using the FüchtbauerLadenburg equation ${ }^{30}$

$$
\sigma_{\mathrm{em}}(\lambda)=\frac{\lambda^{5} I(\lambda)}{8 \pi n^{2} c \tau_{\mathrm{m}} \int \lambda I(\lambda) \mathrm{d} \lambda}
$$

where $I(\lambda)$ is the fluorescence intensity, $n$ is the reflective index, as reported in, ${ }^{12} c$ is the velocity of light, and $\tau_{\mathrm{m}}$ is the measured lifetime, which is presented in the following section. Therefore,

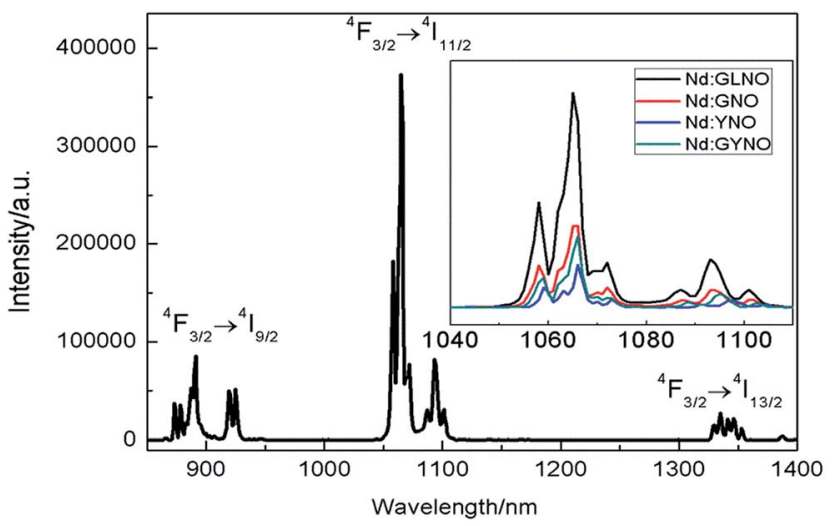

Fig. 7 Fluorescence spectra of the Nd:GLNO crystal at room temperature. Inset: comparison of the FWHM at around $1065 \mathrm{~nm}$ between Nd:GLNO, Nd:GNO, Nd:YNO, and Nd:GYNO crystals. the stimulated emission cross-section value of the Nd:GLNO crystal at $1065 \mathrm{~nm}$ is estimated to be $18 \times 10^{-20} \mathrm{~cm}^{2}$, which is smaller than that of Nd:GYNO and Nd:YNO crystals.

3.3.3 Fluorescence decay curve. The fluorescence decay curves of ${ }^{4} \mathrm{~F}_{3 / 2} \rightarrow{ }^{4} \mathrm{I}_{11 / 2}$ transition at room temperature are shown in Fig. 8. The decay curve can be well fitted with a single exponential function, and fluorescence lifetime is fitted to be $176.4 \mu \mathrm{s}$, which is longer than that of Nd:GYNO and Nd:YNO crystals. The small emission cross-section and long fluorescence lifetime indicates that the Nd:GLNO crystal possesses good energy storage capacity, which is advantageous for its application in a Q-switched laser.

The optical property comparison between Nd:GLNO crystal and other Nd-doped niobate laser crystals is listed in Table 1. As we can see, Nd:GLNO crystal shows good comprehensive spectroscopic and laser performance. Therefore, it is believable that Nd:GLNO crystal has great application potential in low- and moderate-power lasers.

\subsection{Laser performance}

Given that the strongest absorption of the Nd:GLNO crystal was along the $c$-orientation, the crystal with $c$-orientation was chosen to perform the $\mathrm{CW}$ laser characterization using a plano-plano resonator. The output power under various incident pump powers is shown in Fig. 9. It can be observed that the pump threshold is $204 \mathrm{~mW}$, and a maximum output power of $957 \mathrm{~mW}$ at $1065 \mathrm{~nm}$ is obtained at a pump power of $3153 \mathrm{~mW}$. Therefore, the optical-to-optical conversion efficiency was achieved is $30.3 \%$, and a slope efficiency of $34.2 \%$ was derived from the linear fitting to the curve. As shown in Table 1, the slope efficiency of Nd:GLNO is comparable to that of other Nd-doped niobate laser crystals, if not better. However, the slope efficiency of Nd:GLNO is comprehensively lower than that of commercially Nd-doped vanadate laser crystals. The reason for the low laser output power and slope efficiency of Nd:GLNO crystal are listed below: first, the investigation on Nd:GLNO is just in the preliminary stage and higher quality crystals are expected to be obtained in the future studies. Second, the crystal used in the laser

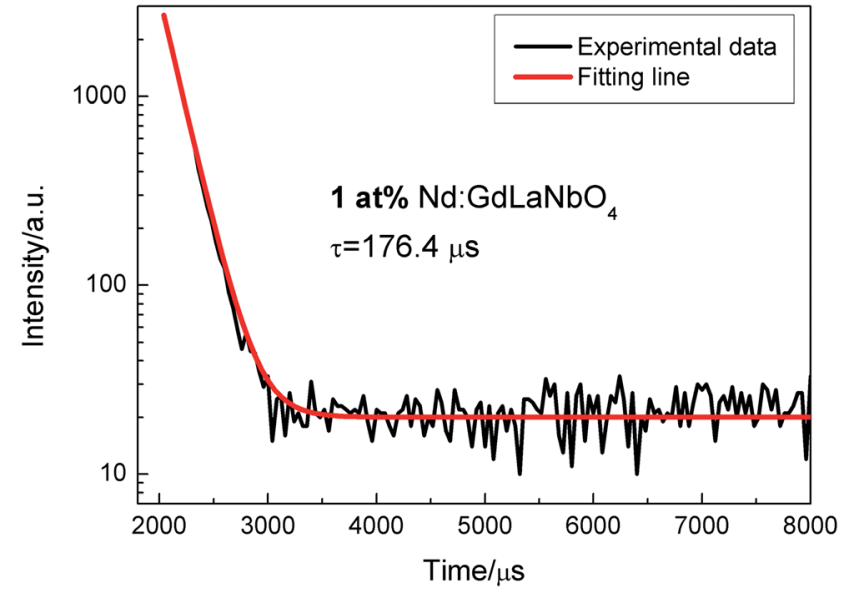

Fig. 8 Fluorescence decay curve of the ${ }^{4} \mathrm{~F}_{3 / 2} \rightarrow{ }^{4} \mathrm{I}_{11 / 2}$ transition. 
Table 1 Optical property comparison between Nd:GLNO crystal and other $\mathrm{Nd}$-doped niobate laser crystals

\begin{tabular}{|c|c|c|c|c|c|c|}
\hline Crystals & FWHM (808 nm) & $\sigma_{\alpha}\left(10^{-20} \mathrm{~cm}^{2}\right)(808 \mathrm{~nm})$ & $\sigma_{\mathrm{em}}\left(10^{-20} \mathrm{~cm}^{2}\right)(1.06 \mu \mathrm{m})$ & $\tau(\mu \mathrm{s})$ & $\eta$ (\%) (slope efficiency) & Ref. \\
\hline Nd:GLNO & 13 & 10.49 & 18 & 176.4 & 34.2 & This work \\
\hline Nd:GYNO & $5-14$ & 11.6 & 20.5 & 156 & 30.4 & 25 \\
\hline Nd:GTO & 6 & 5.1 & 39 & 178 & 36.0 (coated) & 11 \\
\hline Nd:GYTO & $6-12$ & 6.9 & 22 & 182 & 38.5 (coated) & 26 \\
\hline
\end{tabular}

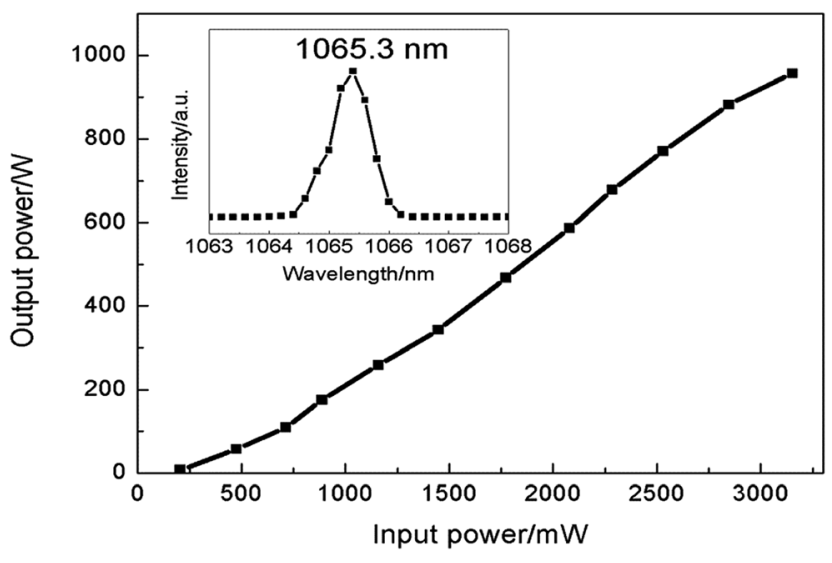

Fig. 9 Laser output power of $\mathrm{Nd}: \mathrm{GdLaNbO}_{4}$ versus incident power. Inset: laser spectrum of the Nd:GLNO crystal at around $1.06 \mu \mathrm{m}$.

experiment is uncoated. Third, the concentration of $\mathrm{Nd}^{3+}$ in the GLNO host is not optimized. Therefore, the laser efficiency of the $\mathrm{Nd}$ :GLNO crystal is expected to improve in the future studies.

\section{Conclusions}

In this study, a new high-quality mixed laser crystal Nd:GdLaNbO ${ }_{4}$ has been grown successfully by the Czochralski method. The unit cell parameters are obtained to be $a=5.381$ $\AA, b=11.112 \AA, c=5.112 \AA, \alpha=\gamma=90^{\circ}$, and $\beta=94.551^{\circ}$ by the Rietveld refinement method. The effective segregation coefficient of $\mathrm{Nd}^{3+}$ ion in the Nd:GLNO crystal is measured to be 0.71 . Room temperature absorption spectra and emission spectra show obvious inhomogeneous broadening, which can be attributed to the disordered structure of the Nd:GLNO crystal. The broad emission spectra and relatively long lifetime indicates that Nd:GLNO is suitable for generating ultrashort pulse lasers. Moreover, $\mathrm{CW}$ laser operation at $1.06 \mu \mathrm{m}$ is demonstrated with $c$-oriented Nd:GLNO crystal for the first time. A maximum output power of $957 \mathrm{~mW}$ is obtained corresponding to an optical-to-optical conversion efficiency of $30.3 \%$ and slope efficiency of $34.2 \%$. All the obtained results indicate that $\mathrm{Nd}$ :GLNO is a very promising laser material.

\section{Acknowledgements}

This work was financially supported by the National Natural Science Foundation of China (Grants No. 51502292, and 61405206).

\section{Notes and references}

1 J. Sanghera, W. Kim, G. Villalobos, B. Shaw, C. Baker, J. Frantz, B. Sadowski and I. Aggarwal, Materials, 2012, 5, 258-277.

2 S. M. Hooker, Nat. Photon., 2013, 7, 775-782.

3 R. Ortiz, S. M. Flores, I. Quintana, M. Vivanco, J. R. Sarasua and J. L. T. Herrera, Mater. Sci. Eng., C, 2014, 37, 241-250.

4 J. Cheng, C. S. Liu, S. Shang, D. Liu, W. Perrie, G. Dearden and K. Watkins, Opt. Laser Technol., 2013, 46, 88-102.

5 P. V. Zarubin, Quantum Electron., 2002, 32, 1048-1064.

6 H. H. Yu, J. H. Liu, H. J. Zhang, A. A. Kaminskii, Z. P. Wang and J. Y. Wang, Laser Photonics Rev., 2014, 8, 847-864.

7 H. J. Zhang, J. H. Liu, J. Y. Wang, C. Q. Wang, L. Zhu, Z. S. Shao, X. L. Meng, X. B. Hu and M. H. Jiang, J. Opt. Soc. Am. B, 2002, 19, 18-27.

8 H. H. Yu, H. J. Zhang, Z. P. Wang, J. Y. Wang, Z. S. Shao, M. H. Jiang and X. Y. Zhang, Opt. Express, 2007, 15, 32063211.

9 H. H. Yu, H. J. Zhang, Z. P. Wang, J. Y. Wang, Y. G. Yu, X. F. Cheng, Z. S. Shao, M. H. Jiang, Z. C. Ling and H. R. Xia, J. Appl. Phys., 2007, 101, 113109.

10 S. J. Ding, F. Peng, Q. L. Zhang, J. Q. Luo, W. P. Liu, D. L. Sun, R. Q. Dou, J. Y. Gao, G. H. Sun and M. J. Cheng, J. Alloys Compd., 2017, 693, 339-343.

11 F. Peng, H. J. Yang, Q. L. Zhang, J. Q. Luo, W. P. Liu, D. L. Sun, R. Q. Dou and G. H. Sun, Appl. Phys. B, 2015, 118, 549-554.

12 S. J. Ding, F. Peng, Q. L. Zhang, J. Q. Luo, W. P. Liu, D. L. Sun, R. Q. Dou and G. H. Sun, Opt. Mater., 2016, 62, 7-11.

13 T. J. Yu, S. K. Lee, J. H. Sung, J. W. Yoon, T. M. Jeong and J. Lee, Opt. Express, 2012, 20, 10807-10815.

14 N. Tolstik, E. Sorokin and I. T. Sorokina, Opt. Express, 2014, 22, 5564-5571.

15 U. Anwar, C. W. Yi and M. Hiroshi, Sci. Prog., 2013, 96, 1-18. 16 J. H. Ha, B. J. Lee, D. J. Hwang and D. Kim, RSC Adv., 2016, 6, 86232.

17 H. H. Xu, S. Han, H. H. Yu, Z. P. Wang, J. Y. Wang, H. J. Zhang and D. Y. Tang, J. Cryst. Growth, 2014, 387, 66-72.

18 Z. B. Pan, J. Ma, H. H. Xu, D. Y. Tang, H. Q. Cai, H. H. Yu, H. J. Zhang and J. Y. Wang, RSC Adv., 2015, 5, 44137.

19 B. L. Wang, L. Tian, H. H. Yu, H. J. Zhang and J. Y. Wang, Opt. Lett., 2015, 40, 3213-3216.

20 H. H. Xu, H. H. Yu, Z. P. Wang, S. Han, Y. C. Wang, Z. B. Pan, Y. Y. Zhang, S. Q. Sun, J. Y. Wang and H. J. Zhang, Opt. Express, 2012, 20, 16524-16531. 
21 V. G. Ostroumov, G. Huber, A. L. Zagumennyi, Y. D. Zavartsev, P. A. Studenikin and I. A. Shcherbakov, Opt. Commun., 1996, 124, 63-68.

22 H. H. Yu, H. J. Zhang, Z. P. Wang, J. Y. Wang, Y. G. Yu, Z. S. Shao, M. H. Jiang and X. Y. Zhang, Appl. Phys. Lett., 2007, 90, 231110.

23 S. Han, H. H. Xu, Y. G. Zhao, L. J. Chen, Z. P. Wang, H. H. Yu, H. J. Zhang and X. G. Xu, Infrared Phys. Technol., 2013, 60, 66-70.

24 S. P. Ng, D. Y. Tang, A. Q. Liu, L. J. Qin and X. L. Meng, Opt. Commun., 2006, 259, 256-260.

25 S. J. Ding, Q. L. Zhang, F. Peng, W. P. Liu, J. Q. Luo, R. Q. Dou, G. H. Sun, X. F. Wang and D. L. Sun, J. Alloys Compd., 2017, 698, 159-163.
26 F. Peng, H. J. Yang, Q. L. Zhang, J. Q. Luo, D. L. Sun, W. P. Liu, G. H. Sun, R. Q. Dou, X. F. Wang and X. Xing, Opt. Mater. Express, 2015, 5, 2536-2544.

27 A. C. Larson and R. B. V. Dreele, General structure analysis system, Los Alamos National Laboratory Report no. LAUR, 2004, vol. 86, p. 748.

28 H. L. Zhang, X. J. Sun, J. Q. Luo, Z. Q. Fang, X. Y. Zhao, M. J. Cheng, Q. L. Zhang and D. L. Sun, J. Alloys Compd., 2016, 672, 223-228.

29 J. Y. Gao, Q. L. Zhang, D. L. Sun, J. Q. Luo, W. P. Liu and S. T. Yin, Opt. Commun., 2012, 285, 4420-4426.

30 I. Sokolska, E. Heumann, S. Kuck and T. Lukasiewicz, Appl. Phys. B, 2002, 71, 893-896. 